\title{
ADSORPTION OF PHENOL FROM AQUEOUS MEDIA BY AN AGRO-WASTE (HEMIDESMUS INDICUS) BASED ACTIVATED CARBON
}

\author{
V.SRIHARI ${ }^{*}-$ ASHUTOSH DAS \\ School of Civil Engineering, SASTRA Deemed University, Thanjavur-613402, India. \\ (phone: +91-4362-264101 - 108; fax: +91-4362-264120) \\ * Corresponding author \\ e-mail:vsrihari@civil.sastra.edu \\ (Received $20^{\text {th }}$ March 2006 ; accepted $6^{\text {th }}$ July 2009)
}

\begin{abstract}
The adsorption of phenol by an agro-waste based activated carbon prepared from the root residue of Hemidesmus Indicus (HIC) was investigated to assess its possible use as adsorbent. The effect of various factors, namely, $\mathrm{pH}$, initial adsorbate concentration, adsorbent dosage and contact time were studied to identify adsorption capacity of HIC. The results were compared to that obtained from adsorption of phenol by commercial activated carbon (CAC). Adsorption data were modeled with the Langmuir and Freundlich isotherms. The kinetic models were also applied for the pseudo-first-order, pseudo-second-order, intra-particle diffusion and pore diffusion coefficients. Although HIC and CAC showed much similar isotherm models and kinetics, yet HIC was found to show much higher boundary layer effect and pore-diffusion coefficients, in relation to CAC.
\end{abstract}

Keywords: Phenol, agro-waste, adsorption, Isotherms, adsorption kinetics

\section{Introduction}

Since 1860, phenol has been in production, with its basic use as an antiseptic. During late $19^{\text {th }}$ century and thereafter the use of phenol has been further extended to the synthesis of dyes, aspirin, plastics, pharmaceuticals, petrochemical and pesticide chemical industries. In fact, by 2001 , the global phenol production has reached an impressive 7.8 million tons [1].

Normally, discharges from the aforesaid phenol-yielding industries find their way to water bodies and subsequently affect the water quality adversely. As per the studies by various authors, phenols and its derivatives have been reported to cause undesirable and deleterious effect in water, even at a concentration as low as $0.1 \mathrm{ppm}$ [2]. In fact, the adverse effects of phenol have been observed on the central nervous system, cardiovascular system as well as urino-genital systems of human being, often expressed by the multiple symptoms: convulsions, coma, cardiac disorders, respiratory failure and collapse [3]. As per literature, the various analytic methods attempted for dephenolation of wastewater include steam stripping, solvent extraction, oxidation $\left(\mathrm{O}_{3}, \mathrm{H}_{2} \mathrm{O}_{2}\right.$, and $\mathrm{ClO}_{2}$ ), ion exchange, biodegradation and adsorption methods $[4,5,6]$. Out of all these, adsorption methods are the most-widely used techniques and activated carbon has been the predominant adsorbent all over the world [7, 8]. However, due to its high cost and low regeneration capacity, since the last three decades, extensive researches have been directed towards investigating the adsorption characteristics and potentials of cheaper materials and solid wastes, such as fly ash, peat, soil, rice husk, sawdust, bagasse and so forth $[9,10,11,12]$.

In the present study, the extracted residue of a root of an Indian plant, namely Hemidesmus indicus (also called Sveta sariva, Ananda mul or Nannari and is popularly used as energy stimulant soft drink), is studied for its adsorption capacity. In fact, 
Hemidesmus indicus has been known to possess various favourable medical characteristics, such as promoting good circulation, clearing toxins, balancing the glandular system, regulating hormone secretion, providing calories, protecting against UV-radiation, stimulating metabolism and curing several stomach and kidney disorders. It has also been indigenously used for water purification (mainly turbidity removal) in certain traditional communities in India. However, the residue of the root of the plant has been considered wastes, with apparently no specific utilization (probably, except combustion and composting to a limited degree). The present paper is aimed at evaluation of the effectiveness of Hemidesmus indicus root residue and determination of its optimization condition for phenol-sorption.

\section{Experimental Methods}

\section{Preparation of activated carbon}

Roots of Hemidesmus indicus, a locally available slender twining herb, was collected and after extraction of its juice by traditional method (of grinding, boiling with water and filtering), was cleaned and washed thoroughly to remove water-soluble substances (so as not to affect the aqueous characteristics of phenolated wastewater). The material was acidulated using 1:1 wt ratio of concentrated $\mathrm{H}_{2} \mathrm{SO}_{4}$ and subsequently allowed to soak for 24 hours at room temperature. Thereafter, the sample materials were placed in an oven and heated to $200{ }^{\circ} \mathrm{C}$ for 24 hours, followed by cooling, washing (with distilled water) and soaking with $1 \% \mathrm{NaHCO}_{3}$ solution (to remove any excess acid). The washing with distilled water was continued till the uniform characteristics of both filtering and filtered water (with respect to colour, $\mathrm{pH}$ and turbidity). The thoroughly washed sample was dried and subsequently subjected to pyrolosis at $850-900{ }^{\circ} \mathrm{C}$ for 30 minutes. The samples, thus obtained, were ground in a ball mill and the particles having an average diameter of $0.5 \mathrm{~mm}$ (using the sieves of 20-50 mesh, ASTM), were collected and stored for further studies.

\section{Characterization of Activated Samples}

Activated carbon, obtained as above, was characterized by adopting the standard procedures $[13,14,15]$. The moisture content of the carbon was determined by heating a known weight of the sample in an air oven maintained at $105 \pm 5^{\circ} \mathrm{C}$ for about $4 \mathrm{~h}$. The residue was ignited in a muffle furnace at $1000^{\circ} \mathrm{C}$ for about $3 \mathrm{~h}$ to determine the ash content. Surface acidity of the sample was studied using boiled water and decolourising power, using methylene blue solution. The adsorption characteristics was studied in terms of phenol number (the amount of carbon required for $90 \%$ removal of phenol, which indicates the ability to remove taste and odour of the activated carbon) and iodine number (the ability of the carbon to adsorb low molecular weight substances, defined as the milligrams of iodine $\left(\mathrm{I}_{2}\right)$ that are adsorbed per gram of carbon when the equilibrium concentration of the bulk saturation $\left(\mathrm{C}_{\mathrm{eq}}\right)$ is $\left.0.02 \mathrm{~N}\right)$. The surface area of the activated carbons was carried by BET (Brunauer Emmett Teller) Nitrogen adsorption method. The characteristics of the activated carbons are presented in Table 1. 
Table 1. Characteristics of HIC and CAC

\begin{tabular}{|l|l|l|}
\hline Property & HIC & CAC \\
\hline Bulk Density $\left(\mathrm{g} . \mathrm{ml}^{-1}\right)$ & 0.48 & 0.65 \\
\hline Moisture content (\%) & 10.35 & 12.57 \\
\hline Ash content (\%) & 2.08 & 2.78 \\
\hline Fixed Carbon (\%) & 97.92 & 97.22 \\
\hline Solubility in water (\%) & 0.80 & 1.55 \\
\hline Solubility in 0.25M HCl acid (\%) & 1.2 & 3.0 \\
\hline pH of 5\% slurry & 6.3 & 8.2 \\
\hline Decolourising power (mg.g $\left.{ }^{-1}\right)$ & 82 & 74 \\
\hline Phenol number $(\mathrm{mg})$ & 5.3 & 5.2 \\
\hline Iodine number $\left(\mathrm{mg} \cdot \mathrm{g}^{-1}\right)$ & 204 & 192 \\
\hline Surface area $\left(\mathrm{m}^{2} \cdot \mathrm{g}^{-1}\right)$ & 627 & 596 \\
\hline
\end{tabular}

\section{Batch experiments}

A $100 \mathrm{ml}$ each of synthetic phenol solution (30 ppm) adjusted to different $\mathrm{pH}$ values by $0.1 \mathrm{~N} \mathrm{NaOH}$ or $0.1 \mathrm{~N} \mathrm{H}_{2} \mathrm{SO}_{4}$, were placed in $250 \mathrm{ml}$ leak-proof reaction bottles and a known amount of Hemidesmus indicus carbon (HIC) was added to each bottle. The solution was equilibrated for 24 hours at room temperature, followed by filtration of the adsorbent and subsequent analysis of filtrate for phenol concentrations were determined by spectrophotometric analysis of the colour resulting from the reaction of phenol with 4- aminoantipyrine at a wavelength of $500 \mathrm{~nm}$ [13]. Kinetic experiments were conducted using a known weight of carbon dosage for a phenol concentration in the range of 5-40 ppm. Periodically, after regular intervals of time, samples were analysed for phenol concentration. The rate constants were calculated by using the various models (viz. pseudo-first-order, pseudo-second-order, intra-particle diffusion and pore diffusion coefficients).

\section{Results and Discussion}

The adsorbent prepared from HIC was studied for adsorption and the results thus obtained were compared with that of CAC and the removal efficiency of phenol from aqueous solution was estimated, under different experimental conditions.

\section{Effect of carbon dosage}

Figure 1 shows the amount of phenol removed as a function of carbon dosage from the solution at neutral $\mathrm{pH}$. Carbon dosage was varied from 5 to $500 \mathrm{mg}$ and equilibrated for 24 hours. As evident from the figure, to remove the entire amount of phenol (with initial concentration of $30 \mathrm{ppm}$ ), the minimum adsorbent dosage required was found to be $35 \mathrm{mg}$ of CAC or $30 \mathrm{mg}$ of HIC. Thus, HIC seems to be better dephenolating agent than CAC. 


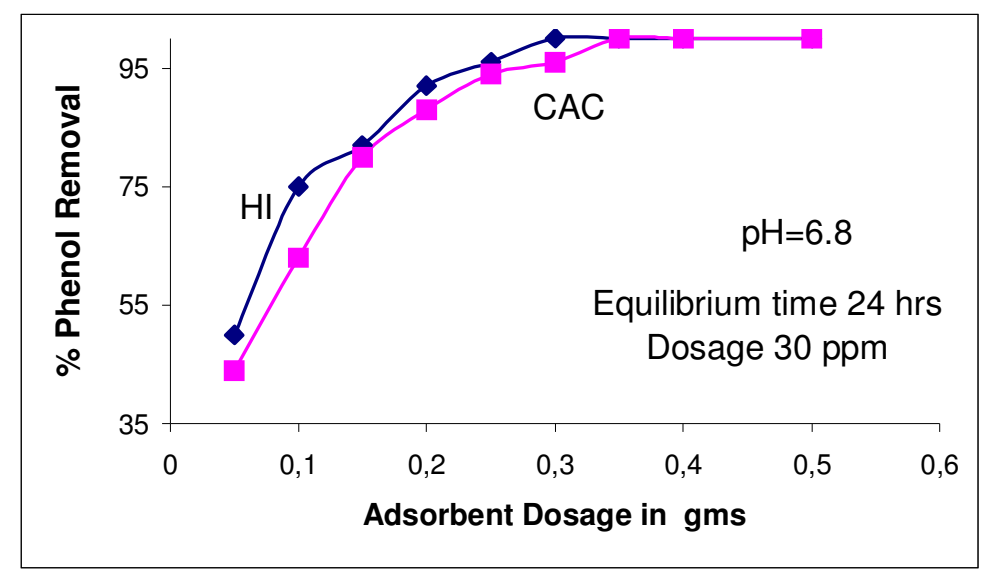

Figure 1. Effect of Adsorbent Dosage

\section{Effect of pH on phenol adsorption}

Since phenolsorption has been reported to be affected by the $\mathrm{pH}$ of the adsorbate [9], the adsorption of phenol by HIC and CAC were studied at various $\mathrm{pH}$ values of the phenol solution $(100 \mathrm{ml}, 30-\mathrm{ppm})$. The amount of phenol adsorbed shows a declining trend with higher as well as with lower $\mathrm{pH}$, with maximum removal of phenol (up to almost $100 \%$ by both the adsorbents) at neutral $\mathrm{pH}$ (Figure 2). This reduction of phenol-sorption may be because of the suppression by hydrogen ions (at lower $\mathrm{pH}$ ), and hydroxyl ions (at higher $\mathrm{pH}$ ) in addition to formation of various phenolic compounds at both acidic and alkaline conditions $[16,17]$.

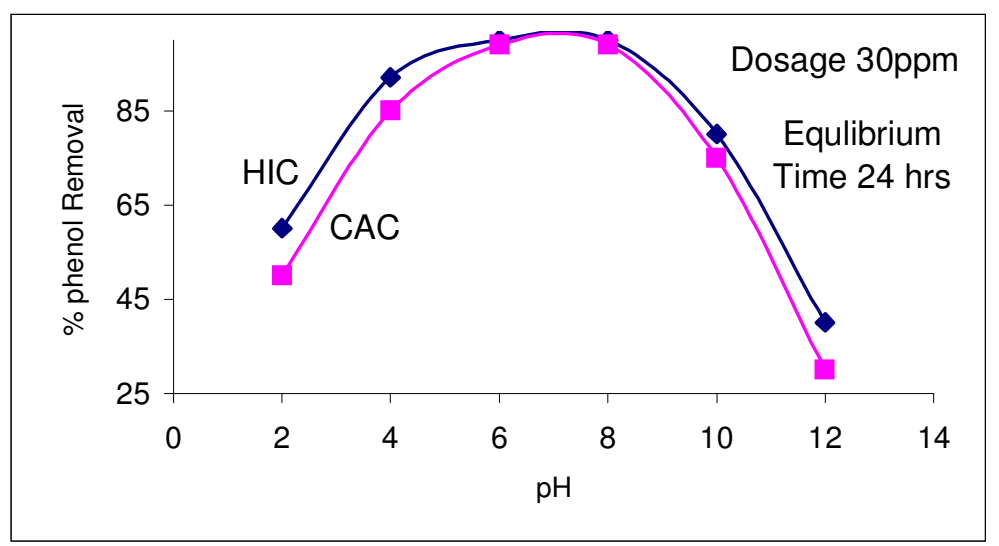

Figure 2. Effect of $p H$ on Phenol Adsorption

\section{Effect of contact time}

Figure 3 shows the effect of contact time on the removal of phenol by HIC and CAC. For different duration of time (ranging from 0.5 to 24 hours), well-shaken phenol solution $(100 \mathrm{ml}, 30 \mathrm{ppm})$ was studied for equilibrium. The study revealed 5 hour and 6 hours as the equilibrium time for HIC and CAC, respectively.

\section{Adsorption Isotherms}

In order to determine the adsorption potential of both the adsorbents (viz. HIC and CAC) for the removal of phenol, study of adsorption isotherm was carried out and 
tested against the Freundlich and Langmuir isotherm models, using standard procedures used by various authors $[9,18,19]$.

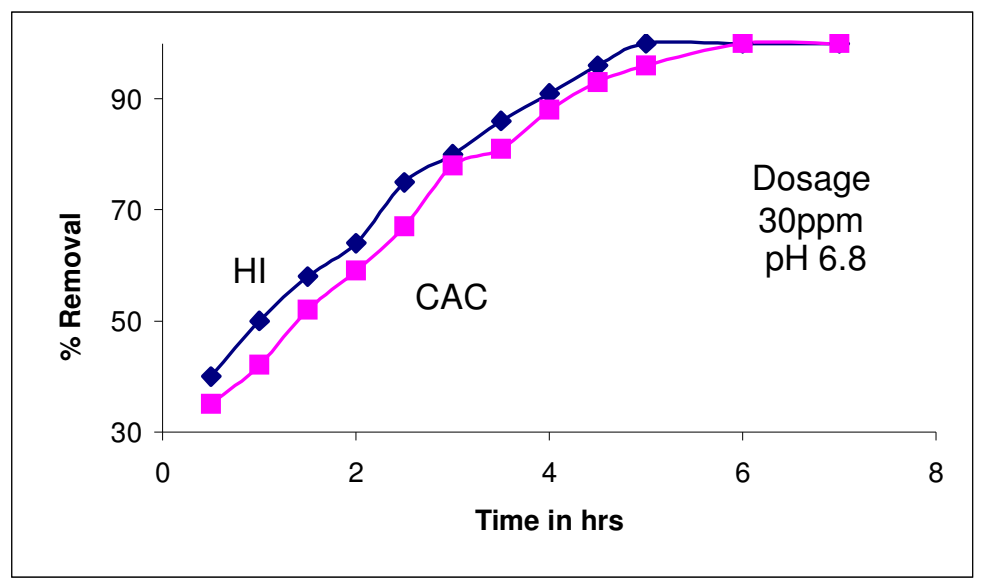

Figure 3. Effect of Time on phenol Adsorption

\section{Langmuir Isotherm:}

The Langmuir equation is given as:

$$
\frac{C_{e}}{q}=\left(\frac{1}{Q_{0} b}\right)+\left(\frac{C_{e}}{Q_{0}}\right)
$$

Where, $\mathrm{q}=\mathrm{x} / \mathrm{m}$, represents the amount of adsorbate adsorbed per unit mass of adsorbent $(\mathrm{mg} / \mathrm{g})$ and ' $\mathrm{C}_{\mathrm{e}}$ ', ' $\mathrm{Q}_{0}$ and ' $\mathrm{b}$ ' refer to the equilibrium concentration $(\mathrm{ppm})$, monolayer adsorption capacity $(\mathrm{mg} / \mathrm{g}$ ) and surface energy $(\mathrm{g} / \mathrm{l})$, respectively. A plot of $\mathrm{Ce} / \mathrm{q}$ verses $\mathrm{Ce}$ as shown in Figure 4 , where ' $1 /\left(\mathrm{b} \mathrm{Q}_{0}\right)$ ' and ' $1 / \mathrm{Q}_{0}$ ' correspondingly represent the intercept and slope (comparing with the normal equation for straight line as ' $y=m x+c$ ').

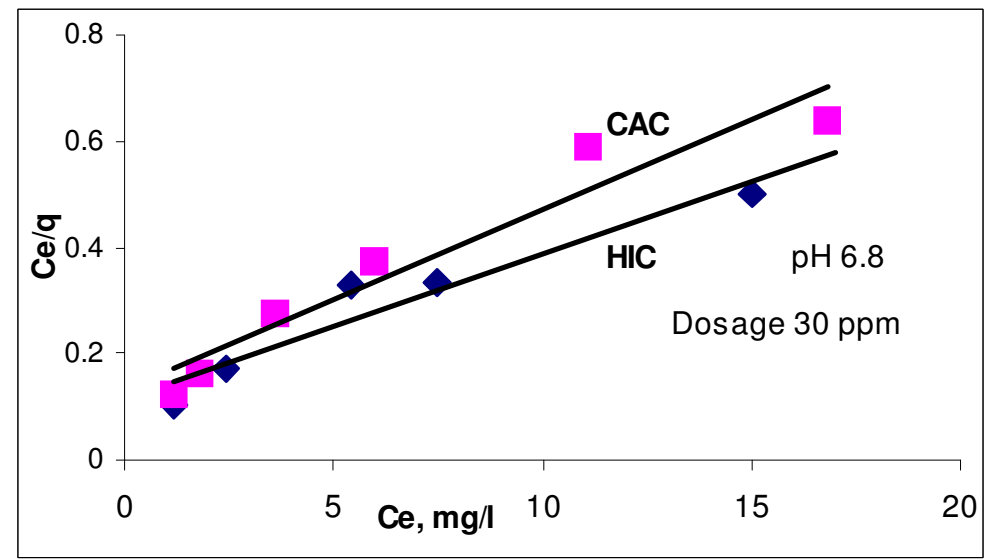

Figure 4. Langmuir Adsorption Isotherm for Phenol

The Langmuir isotherm can also be expressed by a separation factor $\left(\mathrm{R}_{\mathrm{L}}\right)$, which is given by the equation [20].

$$
\mathrm{R}_{\mathrm{L}}=1 /\left(1+\mathrm{b} . \mathrm{C}_{\mathrm{i}}\right)
$$


Where, ' $\mathbf{C}_{\mathbf{i}}$ ' is the initial concentration of phenol in ppm and ' $\mathbf{b}$ ' is the Langmuir constant in $\mathrm{g} / \mathrm{l}$. The separation factor ' $\mathbf{R}_{\mathbf{L}}$ ' indicates the nature of the adsorption process as given in Table 2 .

Table 2. The process nature of separation factor.

\begin{tabular}{|c|c|c|}
\hline S.No. & $\mathbf{R}_{\mathbf{L}}$ Value & Type of process \\
\hline 1 & $\mathrm{R}_{\mathrm{L}}>1$ & Unfavourable \\
\hline 2 & $\mathrm{R}_{\mathrm{L}}=1$ & Linear \\
\hline 3 & $0<\mathrm{R}_{\mathrm{L}}<1$ & Favourable \\
\hline 4 & $\mathrm{R}_{\mathrm{L}}=0$ & Irreversible \\
\hline
\end{tabular}

Freundlich Isotherm: The Freundlich equation is expressed as

$$
\frac{x}{m}=q_{e}=k C_{e}^{1 / n}
$$

Where, ' $\mathbf{k}$ ' and ' $\mathbf{n}$ ' are the measures of adsorption capacity and intensity of adsorption. ' $\mathbf{q} \mathbf{e}$ ' is the amount of phenol adsorbed per unit mass of adsorbent and ' $\mathbf{C}_{\mathbf{e}}$ ' is the equilibrium concentration in ppm. The logarithmic form of Freundlich equation can be expressed by

$$
\log (\mathrm{x} / \mathrm{m})=\log \mathrm{q}_{\mathrm{e}}=\log \mathrm{k}+1 / \mathrm{n} \log \mathrm{C}_{\mathrm{e}}
$$

From the straight line (obtained by plotting ' $\log (\mathbf{x} / \mathbf{m})$ ' against ' $\log \mathbf{C}_{\mathbf{e}}$ ' as shown in Figure 5 the corresponding slope and intercept can be determined from ' $1 / \mathbf{n}$ ' and 'log k' values. Table 2 indicates the values of Langmuir and Freundlich constants.

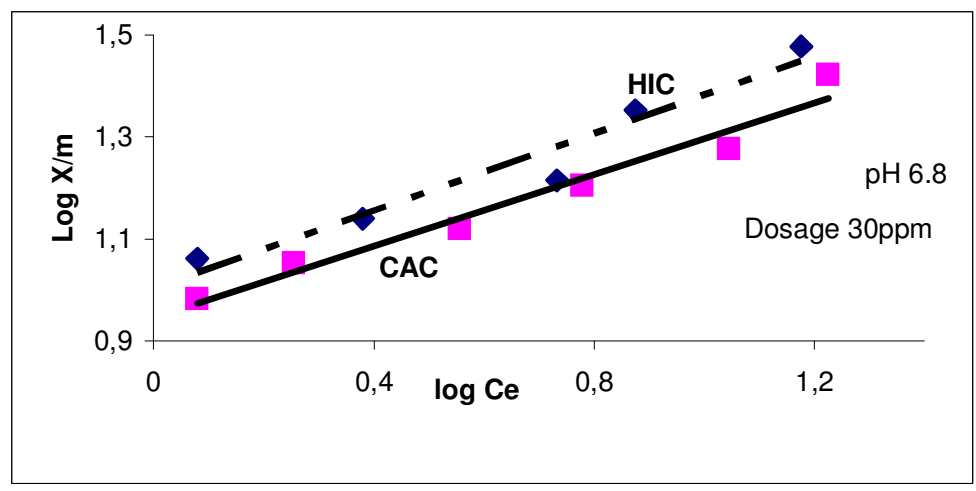

Figure 5. The Freundlich Adsorption Isotherm for Phenol

The results reveal that the adsorption of phenol on HIC and CAC obeys both Freundlich and Langmuir adsorption isotherms, as indicated by high $\boldsymbol{R}^{2}$ Values $(>92 \%)$. Greater the value of $\mathbf{k}$ (the Freunlich constant), higher the phenol uptake from aqueous solution $[9,18]$. As shown in Figure 5, higher $\boldsymbol{k}$-value of HIC $(1.04 \mathrm{mg} / \mathrm{g})$ indicates greater affinity for phenol compared to that of CAC $(0.57 \mathrm{mg} / \mathrm{g})$, which shows better effectiveness of the phenol-HIC system than phenol-CAC system. The adsorption 
intensity, ' $\mathbf{n}$ ' is found to be 2.65 and 2.84 for HIC and CAC, respectively. It is observed that, in both these systems, the $\mathbf{n}$-values satisfy the condition(s) of heterogeneity, i.e., $1<$ $\mathrm{n}<10$ as well as $0<1 / \mathrm{n}<1$ [16]. The higher magnitude of ' $\boldsymbol{Q}_{\mathbf{0}}$ ' indicates that the amount of phenol per unit weight of sorbent (to form a complete monolayer on the surface) seems to be significantly higher for phenol-HIC and phenol-CAC systems. A relatively lower ' $\mathbf{b}$ ' - value $(<0.3)$ implies low surface energy in both the systems, thus indicating a probable stronger bonding between phenol and sorbents [18]. In fact, fairly low to moderate ' $\mathbf{b}$ ' - values have been reported in many of the sorbent-phenol systems, involving palm-seed-coat-activated-carbon, bentonite, and rice husk $[9,11$, and 19].

\section{Adsorption kinetics}

Kinetics of adsorption, a standard analysis in defining adsorption efficiency, describes the solute uptake rate, which in turn governs the residence time of adsorption reaction. The study the adsorption kinetics of the two phenol-sorbent systems (viz. -HIC and -CAC) were carried out using batch experiments. The adsorbents $(0.3 \mathrm{~g})$ were separately exposed to the synthetic phenol solution $(100 \mathrm{ml}, 30 \mathrm{ppm})$ and the amount of phenol adsorbed was estimated for a time period of $30 \mathrm{~min}$ to $360 \mathrm{~min}$. ( or, 6 hours, which refers to the equilibrium time, Figure 1.)

Table 3. Details of Isotherm Constants

\begin{tabular}{|c|c|c|c|c|c|c|c|}
\hline \multirow{2}{*}{ Name of Adsorbent } & \multicolumn{3}{|c|}{ Langmuir Constants } & \multicolumn{3}{c|}{ Freundlich Constants } & $\begin{array}{c}\text { Separation } \\
\text { Factor }\end{array}$ \\
\cline { 2 - 8 } & $\mathrm{Q}_{0}$ & $\mathrm{~b}$ & $\mathrm{R}^{2}$ & $\mathrm{k}$ & $\mathrm{n}$ & $\mathrm{R}^{2}$ & $\mathrm{R}_{\mathrm{L}}$ \\
\hline $\begin{array}{c}\text { Hemidesmus Indicus } \\
\text { Carbon (HIC) }\end{array}$ & 370.37 & 0.23 & 0.92 & 1.04 & 2.65 & 0.94 & 0.12 \\
\hline $\begin{array}{c}\text { Commercial Activated } \\
\text { Carbon (CAC) }\end{array}$ & 294.11 & 0.26 & 0.93 & 0.57 & 2.84 & 0.96 & 0.11 \\
\hline
\end{tabular}

Pseudo- First - Order Kinetics: A widely-used Lagergren model was employed to study the pseudo first order kinetics [21,22, 23].

$$
\frac{d q_{t}}{d t}=k_{1}\left(q_{e}-q_{t}\right)
$$

where ' $\mathbf{q}_{\mathbf{e}}$ ' and ' $\mathbf{q}_{\mathbf{t}}$ ' refers to the amounts of phenol (ppm) adsorbed on the activated carbon at equilibrium time and time $\mathbf{t}(\mathrm{min})$ and $\mathbf{k}_{\mathbf{1}}$ as rate constant $\left(\mathrm{min}^{-1}\right)$, respectively .

Integrating the above equation between the limits from $t=0$ to $t=t$ and from $q_{t}=0$ to $q_{t}$

$=\mathrm{q}_{\mathrm{t}}$

$$
\log \left(q_{e}-q_{t}\right)=\log q_{e}-\frac{k_{1}}{2.303} t
$$


Thus, the rate constants $\left(\mathbf{k}_{1}\right)$ were obtained from slope of the plots of $\log (\mathbf{q e}-\mathbf{q t}) \mathrm{Vs} \mathbf{t}$ $\left(\mathrm{R}^{2}>0.9\right.$, Eq.6) and presented in Table 4. HIC was found to be better rate-limited (0.0104) by pseudo-first order model, than CAC (0.0092).

Table 4. Rate constants for the phenol removal by HIC and CAC

\begin{tabular}{|l|l|l|l|l|l|l|}
\hline \multirow{2}{*}{ Type of Carbon } & \multicolumn{3}{|c|}{ Pseudo-First-Order model } & \multicolumn{3}{c|}{ Pseudo-Second-Order model } \\
\cline { 2 - 7 } & $\mathrm{qe}$ & $\mathrm{R}^{2}$ & $\mathrm{k}_{1}\left(\mathrm{~min}^{-1}\right)$ & $\mathrm{k}_{2}$ (g/mg.min) & $\mathrm{h}(\mathrm{mg} / \mathrm{g} \cdot \mathrm{min})$ & $\mathrm{R}^{2}$ \\
\hline $\begin{array}{l}\text { Hemidesmus } \\
\begin{array}{l}\text { Indicus } \\
\text { Carbon(HIC) }\end{array}\end{array}$ & 16.10 & 0.93 & 0.0104 & 0.0003 & 0.4166 & 0.97 \\
\hline $\begin{array}{l}\text { Commercial } \\
\text { Activated } \\
\text { Carbon(CAC) }\end{array}$ & 11.01 & 0.94 & 0.0092 & 0.0002 & 0.3246 & 0.94 \\
\hline
\end{tabular}

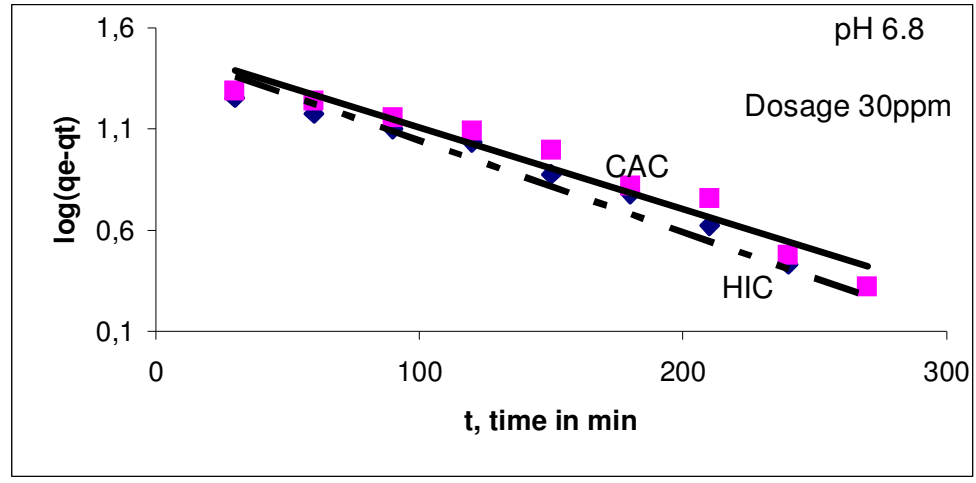

Figure 6. Pseudo-First-Order Kinetics for HIC and CAC

\section{Second order Kinetics:}

The sorption data were also studied by second order kinetics [24,21]

$$
\frac{d q_{t}}{d t}=k_{2}\left(q_{e}-q_{t}\right)^{2}
$$

Where, ' $\mathbf{k}_{\mathbf{2}}$ ' refers to the rate constant of second order adsorption (g/mg.min). On Integration,

$$
\frac{t}{q_{t}}=\frac{1}{k_{2} q_{e}^{2}}+\frac{t}{q_{e}}
$$

Expressing in the form of a standard straight-line equation $(y=m x+c)$;

$$
\frac{t}{q_{t}}=\frac{1}{h}+\frac{t}{q_{e}} \text {, ' } h \text { ' being } k_{2} q_{e}^{2} \text {. }
$$

The plot of t/qt vs $\mathbf{t}$ (Figure 7) gives a linear relationship $\left(\mathrm{R}^{2}>0.9\right)$, from which the constants $\mathbf{k}_{\mathbf{2}}, \mathbf{q}_{\mathbf{e}}$ and $\mathbf{h}$ were determined (Table 3 ). As in the case of the pseudo-first order model, the present analysis also indicate HIC as marginally better rate-limited (0.0003) by pseudo-second order model, than CAC (0.0002). 


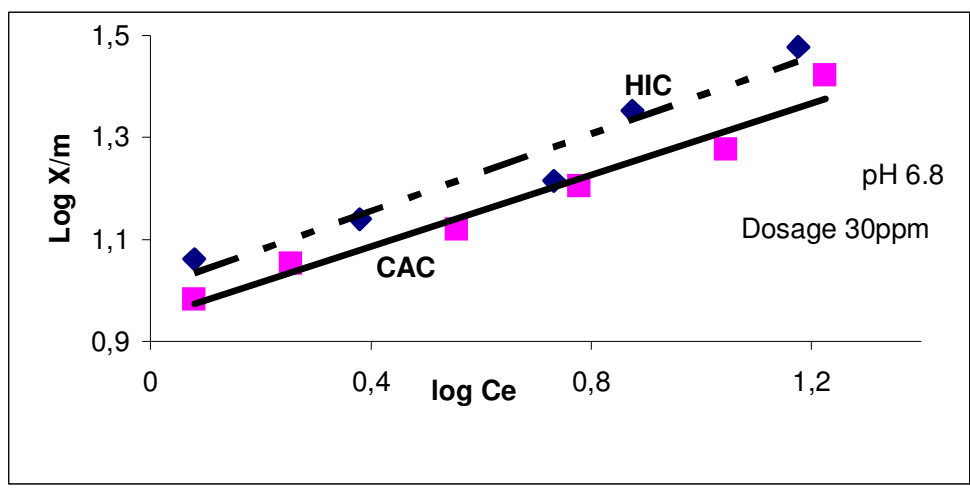

Figure 7. Pseudo-Second-Order Kinetics for HIC and CAC

\section{Intra-particle diffusion}

The structure of the adsorbent and its interaction with the diffusing adsorbate (Intraparticle diffusion) influence the rate of transport, where the solute movement is a function of concentration gradient [25] and the rate constant (ki) can be determined by Intra-particle diffusion model [26].

$$
\mathrm{q}_{\mathrm{t}}=\mathrm{k}_{\mathrm{i}} \mathrm{t}^{(0.5)}+\mathrm{C}
$$

Where, $\mathbf{q}_{\mathbf{t}}$ refers to the amount of phenol adsorbed in $\mathrm{mg} / \mathrm{g}$ at time, $\mathbf{t}$; intercept $\mathbf{C}$, indicating the boundary layer effect [27] and $\mathbf{k}_{\mathbf{i}}$, the Intra-particle diffusion rate constant $\left(\mathrm{mg} / \mathrm{g} \cdot \min ^{1 / 2}\right)$. A plot between the amount of phenol adsorbed and square root of time gives the rate constant (Figure 8, Table 4). The results indicate the intra-particle diffusion as a rate-determining step for HIC and CAC. The boundary layer effect of HIC (5.19) was found to be more than twice to that of CAC (2.16).

The pore diffusion coefficient, D, for the removal of phenol by HIC and CAC were calculated (assuming a spherical-geometry of the adsorbents; 20-50 ASTM; average mesh size $0.5 \mathrm{~mm})$ :

$$
\mathrm{t}_{1 / 2}=0.03 \mathrm{r}_{\mathrm{o}}^{2} / \mathrm{D}
$$

Where, $\mathbf{t}_{1 / 2}$ refers to the time for half adsorption (sec); $\mathbf{r}_{\mathbf{0}}$, the diameter of the particle $(\mathrm{cm}) ; \mathbf{D}$, the pore diffusion constant $\left(\mathrm{cm}^{2} / \mathrm{s}\right)$.

Pore diffusion in the adsorbents (Table 5) is assessed to be less significant due to relatively higher values of the coefficients, in contrast to the rate-limiting range $\left(10^{-11}\right.$ to $\left.10^{-13} \mathrm{~cm}^{2} / \mathrm{s}\right)$ [28]. However, the pore diffusion coefficient for HIC $\left(2.08 \times 10^{-8} \mathrm{~cm}^{2} / \mathrm{s}\right)$ shows almost 1.5 times that for CAC $\left(1.39 \times 10^{-8} \mathrm{~cm}^{2} / \mathrm{s}\right)$.

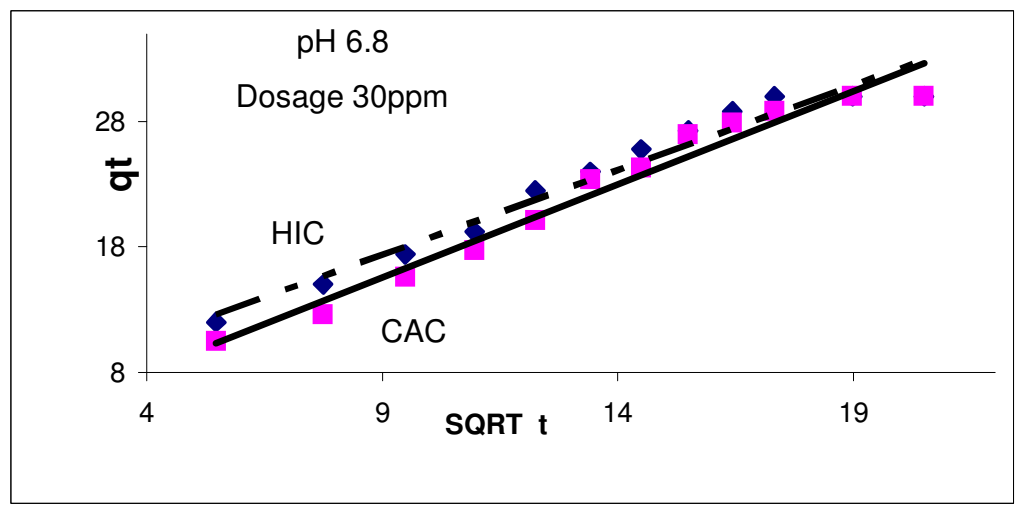

Figure 8. Intra-particle Diffusion plot of phenol on HIC and CAC 
Table 5. Intra particle and pore diffusion constants

\begin{tabular}{|l|c|l|l|l|}
\hline \multirow{2}{*}{ Type of Carbon } & \multicolumn{2}{|l|}{ Intra-particle Diffusion model } & \multicolumn{2}{l|}{$\begin{array}{l}\text { Pore Diffusion } \\
\text { Coefficient }\end{array}$} \\
\cline { 2 - 5 } & $\mathrm{C}$ & $\mathrm{R}^{2}$ & $\begin{array}{l}\mathrm{k}_{\mathrm{i}}(\mathrm{mg} / \mathrm{g} . \\
\left.\mathrm{min}^{1 / 2}\right)\end{array}$ & $\mathrm{D}\left(\mathrm{cm}^{2} / \mathrm{s}\right)$ \\
\hline $\begin{array}{l}\text { Hemidesmus } \\
\text { Indicus Carbon } \\
\text { (HIC) }\end{array}$ & 5.19 & 0.95 & 1.35 & $2.08 \times 10^{-8}$ \\
\hline $\begin{array}{l}\text { Commercial } \\
\text { Activated Carbon } \\
\text { (CAC) }\end{array}$ & 2.16 & 0.96 & 1.48 & $1.39 \times 10^{-8}$ \\
\hline
\end{tabular}

\section{Conclusions:}

The present studies indicate Hemidesmus indicus Carbon (HIC) as a better adsorbent than the commercial activated carbon (CAC), as indicated by its higher adsorption at lower adsorption dosage (and period of equilibrium). Adsorption characteristics of HIC and that of CAC showed notable similarity as reflected by (i) their obedience to both Langmuir and Frueundlich isotherm models, (ii) similar rate-characteristics (in both first- and second- order kinetics, with correlation coefficients greater than 0.9), (iii) ratedetermining character of intra-particular diffusion, and (iv) less significant role by porediffusion process. However, HIC was found to be marginally better rate-limited (than CAC) by both pseudo-first and pseudo-second order models. Besides, 'the boundary layer effect of' and 'the pore diffusion coefficient for' HIC was found to be almost double to and 1.5 times of CAC, respectively.

Acknowledgements: The authors express their sincere thanks to Depart of Science and Technology (DST), New Delhi, for sanctioning this project, and also express their sincere gratitude to their Vice chancellor, Prof R. Sethuraman, SASTRA Deemed University, Thanjavur for providing facilities at our campus.

\section{REFERENCES}

[1] Phenol (2002) - Chemical Week 164: 31.

[2] Mahajan, S.P.(1994) Pollution Control in Processes Industries, - Tata McGraw-Hill, New Delhi.

[3] Agency for Toxic Substances and Disease Registry (ATSDR) (1998) Toxicological profile for phenol. Atlanta, GA: U.S. Department of Health and Human Services, Public Health Service.

[4] Lanouette, K.H. (1977): Treatment of Phenolic Wastes. - Chem Eng. 84(22): 99-106.

[5] Spiker, J. K., Crawford, D. L, Thiel, E. J. (1992): Oxidation of Phenolic and Nonphenolic Substrates by the Lignin Peroxidase of Streptomyces viridosporus. - Appl. Microbiol. Biotechnol. 37: 518-523.

[6] Srihari, V., Das Ashutosh, (2005):Study On Adsorption Of Phenol From Aqueous Media Using Extracted Residue Of Hemidescus Indicus. - Asian Journal of Microbiology Biotechnology \& Environmental Science 7(3): 469-472. 
[7] Mostafa, M.R, Sarma, S.E., Yousef, A.M (1989): Removal of Organic Pollutants from Aqueous Solution. Part-1, Adsorption of Phenol by Activated Carbon. - Indian J. Chem. 28A: 94-98.

[8] El-Geundi, (1997): M.S. Adsorbents for Industrial Pollution control. - Adsorp Sci Technol, 15: 777-787.

[9] Rengaraj, S, Seuny-Hyeon, M. and Sivabalan, R. (2002): Agricultural Solid Waste for the Removal of Organics: Adsorption of phenol from Water and Wastewater by Palm Seed Coat Activated Carbon. - Waste Management 22: 543-548.

[10] Street, M., Patrick, J.W. and. Camporro-perez, M.J. (1995): Sorption of Phenol and pchlorophenol from Water using Convention and Novel Activated Carbons. - Water Sci. Res. 29: 467.

[11] Banat, F.A.Al-Bashir, B. Al-Asheh S and Hayajneh, O. (2000): Adsorption of Phenol by Bentonite - Environmental Pollution 107: 391-398.

[12] Kummar, S., Upadhyay, S.N and Upadhyay, Y.D. (1987): Removal of phenols by adsorption on fly ash. - J. Chem. Technol. Biotechnol. 37: 281.

[13] APHA, AWWA, WEF, (1995):.Standard Methods for the Examination of Water and Wastewater. $19^{\text {th }}$ Edn. - Washington.

[14] ISI (1989): Activated Carbon, Powdered and Granular-Methods of Sampling and Tests. Bureau of Indian Standards, New Delhi, IS 877.

[15] Vogel, A.I. (1969): A Text Book of Quantitative Inorganic Analysis, $3^{\text {rd }}$ Edition - ELBS, London.

[16] Khalid, N., Ahmad, S.and Toheed, (2000): A Potential of Rice Husk for Antimony Removal. - Applied Radiation and Isotopes 52: 30-38.

[17] Singh, B.K., Mishra, N.M., Rawat, N.S. (1994): Sorption Characteristics of Phenols on Fly Ash and Impregnated Fly Ash. - Indian jr of Environ. Health 36: 1-7.

[18] Aksu, Z and Yener, J. (2001): A comparative adsorption/biosorption study of monochlorinated phenols onto various sorbent. - Waste management 21: 695-702.

[19] Mahvi, A.H., Maleki, A. and Eslami, A. (2004): Potential of Rice Husk and Rice Husk Ash for Phenol Removal in Aqueous Systems. - American Journal of Applied Sciences 1(4): 321-326.

[20] Weber, T.W. and Chakravorti, R.K. (1974): Pore and Solid diffusion model for fixed bed adsorbent. - J. Am. Inst. Chem. Engg. 2: 228-238.

[21] Tseng, R.L., Wu, F.C. and Juang, R S (2003): Liquid-phase Adsorption of Dyes and Phenols using Pinewood Based Activated Carbons. - Carbon 41: 487-495.

[22] Chiou, M.S. and Li, H.Y. (2003): Adsorption Behaviour of Reactive Dye in Aqueous Solution on Chemical Cross Linked Chitosan Beads. - Chemosphere 50: 1095-1105.

[23] Ho Yuh-Shan (2004): Citation review of Lagergren kinetic rate equation on adsorption reactions. Scientometrics. - Akadémiai Kiadó, co-published with Springer Science + Business Media B.V., Formerly Kluwer Academic Publishers B.V. 59 (1):171 -177.

[24] Wu, F.C., Tseng, R.L. and Jung, R.S. (2002): Adsorption of Dyes and Humic Acid from Water using Chitosan-Encapsulated Activated carbon. - J. Chem. Technol. Biotech. 77: 1269-1279.

[25] Treybal, E., Robert (1981): Mass Transfer Operations, 3rd Edition, - Mc Graw-Hill, Inc., NY

[26] Nagarethinam, K. and Mariappan, M. (2002): Adsorption of Congo-red on Various Activated Carbons. - Water, Air and Soil Pollution 138: 289-305.

[27] Annadurai, G. and Krishnan, M.R.V. (1997): Adsorption of Acid Dye from Aqueous Solution by Chitin: Equlibrium Studies, - Indian Journal of Chemical Technology 4: 217222.

[28] Michelson, L D., Gideon, P.G., Pace, E.G., Kutal, L.H. (1975): Removal of Soluble Mercury from Wastewater by Complexing Techniques, - US Department Of Industry, Office Of Water Research And Technology, Bulletin 74. 